\title{
Equal-Channel Angular Pressing and High-Pressure Torsion of Pure Copper: Evolution of Electrical Conductivity and Hardness with Strain
}

\author{
Kaveh Edalati ${ }^{1,2, *}$, Kazutaka Imamura ${ }^{3}$, Takanobu Kiss ${ }^{3}$ and Zenji Horita ${ }^{1,2}$ \\ ${ }^{1}$ Department of Materials Science and Engineering, Faculty of Engineering, Kyushu University, Fukuoka 819-0395, Japan \\ ${ }^{2}$ WPI, International Institute for Carbon-Neutral Energy Research (I ${ }^{2}$ CNER), Kyushu University, Fukuoka 819-0395, Japan \\ ${ }^{3}$ Department of Electerical Engineering, Faculty of Engineering, Kyushu University, Fukuoka 819-0395, Japan
}

Pure $\mathrm{Cu}(99.99 \%)$ is processed by equal-channel angular pressing (ECAP) and by high-pressure torsion (HPT). The electrical resistivity as well as the microhardness increases with an increase in the equivalent strain at an early stage of straining, but saturates to a steady state at the equivalent strains more than $\sim 20$. At the steady state, the samples processed by ECAP and HPT show a significant increase in the hardness $(\sim 270 \%)$ but little decrease in the electrical conductivity $(\sim 12 \%)$ when compared to the annealed state. Transmission electron microscopy confirms that the microstructure does not change at the saturated level with further straining. Evolutions of hardness, electrical conductivity and microstructures are also investigated after post-HPT annealing. [doi:10.2320/matertrans.MD201109]

(Received June 30, 2011; Accepted August 9, 2011; Published September 21, 2011)

Keywords: severe plastic deformation, equal-channel angular pressing, high-pressure torsion, ultrafine grain, electrical conductivity

\section{Introduction}

Processing via severe plastic deformation (SPD) to achieve ultrafine grained (UFG) materials has been an attractive research topic in last three decades. ${ }^{1,2)}$ Different SPD methods have been utilized for processing of metallic materials. They are equal-channel angular pressing (ECAP) ${ }^{3,4)}$ high-pressure torsion (HPT), ${ }^{5,6)}$ and accumulative roll-bonding (ARB). ${ }^{7}$ The grain size is significantly refined through the SPD and thus superior mechanical properties are often observed in the SPD-processed metallic materials. ${ }^{1-11)}$ High purity $\mathrm{Cu}$ is a typical material in many studies in the field of SPD processing. ${ }^{12-23)}$

Pure $\mathrm{Cu}$ is the most important representative of electrical engineering materials because of its high electrical conductivity. However, a major limitation of pure $\mathrm{Cu}$ is that it has low strength and low strength-to-weight ratio. Recent studies have shown that both high strength and high electrical conductivity are attained in metallic materials through the application of different SPD processes, ${ }^{21-36)}$ and thus, the SPD processes can be especially attractive for electrical industries. The evolution of mechanical properties and electrical conductivity with strain has been well investigated in pure $\mathrm{Cu}$ processed by $\mathrm{ECAP}^{21-23)}$ and ARB. ${ }^{32-34)}$ However, despite numerous papers regarding the microstructural features and mechanical property improvement of HPT-processed $\mathrm{Cu},{ }^{12-19)}$ there have been no reports on the evolution of electrical conductivity in $\mathrm{Cu}$ after processing by HPT.

In this study, thus, pure $\mathrm{Cu}$ is severely deformed by HPT over a wide range of strain and evolutions of microstructures and microhardness are investigated with a special attention on electrical conductivity. The microhardness and electrical conductivity of the ECAP-processed and post-HPT annealed $\mathrm{Cu}$ samples are also investigated.

${ }^{*}$ Corresponding author, E-mail: Kaveh.edalati@zaiko6.zaiko.kyushu-u. ac.jp

\section{Experimental Materials and Procedures}

High purity copper (99.99\%) was received in the form of a cold-extruded rod with $10 \mathrm{~mm}$ diameter and $1250 \mathrm{~mm}$ length, and in the form of a cold-rolled plate having dimensions of $10 \mathrm{~mm} \times 100 \mathrm{~mm} \times 200 \mathrm{~mm}$. The rod was cut to shorter rods with $65 \mathrm{~mm}$ length for ECAP processing. The plate was cut to cylinders with $10 \mathrm{~mm}$ diameter and $10 \mathrm{~mm}$ height and to inner-hollow cylinders with inner and outer diameters of $24 \mathrm{~mm}$ and $30 \mathrm{~mm}$ using a wire-cutting electrical discharge machine. They were further sliced to discs and rings with thicknesses of $0.8 \mathrm{~mm}$ for HPT processing. All samples having the forms of rods, discs and rings were annealed for $1 \mathrm{~h}$ at $873 \mathrm{~K}$ to give an initial grain size of $\sim 150 \mu \mathrm{m}$. Microstructure taken with optical microscopy after annealing is shown in Fig. 1.

ECAP was carried out using the facility as described in Ref. 12). ECAP was conducted using route $\mathrm{Bc}$ on the rods at room temperature for either $N=1,2,4,8,12$ or 20 passes through a die, having a channel diameter of $10 \mathrm{~mm}$, a channel angle of $\Phi=90^{\circ}$ and an angle for the outer arc of curvature

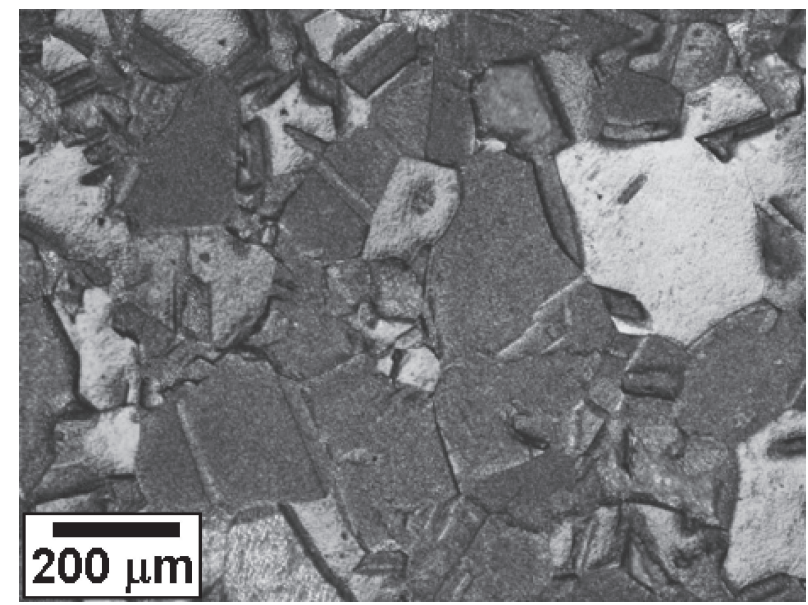

Fig. 1 Optical micrographs of sample after annealing at $873 \mathrm{~K}$ for $1 \mathrm{~h}$. 
of $\Psi=20^{\circ}$. The equivalent strain, $\varepsilon$, for ECAP process is determined by the following equation ${ }^{37)}$

$$
\varepsilon=\frac{N}{\sqrt{3}}\left[2 \cot \left(\frac{\Phi}{2}+\frac{\Psi}{2}\right)\right]+\Psi \operatorname{cosec}\left[\left(\frac{\Phi}{2}+\frac{\Psi}{2}\right)\right]
$$

HPT was conducted using the facilities as described in Refs. 38, 39) for disc and ring samples. The facilities for HPT consist of upper and lower anvils having a shallow hole of $10 \mathrm{~mm}$ diameter and $0.25 \mathrm{~mm}$ depth at the center for the disc sample. For the ring sample, the upper and lower anvils have a shallow circular groove with the inner and outer diameters of $24 \mathrm{~mm}$ and $30 \mathrm{~mm}$ with the groove depth of $0.25 \mathrm{~mm}$ around the center. Each sample was placed on the hole or on the groove and the upper and lower anvils were rotated with respect to each other at room temperature with a rotation speed of $\omega=0.5 \mathrm{rpm}$ under a pressure of $P=2 \mathrm{GPa}$. The rotation was terminated after revolutions of either $N=$ $1 / 4,1 / 2,3 / 4,1,2,4,5,10,12,16$ or 20 . Disc samples subjected to HPT for 1 and 12 revolutions were annealed for $2 \mathrm{~h}$ at $433 \mathrm{~K}$ and $513 \mathrm{~K}$. In this study, the values of slippage fraction and thickness reduction during HPT were measured as described earlier. ${ }^{40,41)}$ Since both slippage and thickness reductions during HPT were less than $12 \%$ for any numbers of revolutions, the equivalent strain was calculated as ${ }^{8)}$

$$
\varepsilon=\frac{2 \pi r N}{\sqrt{3} h}
$$

where $r$ is the distance from the disc center and $h$ is the thickness of the disc and ring samples.

The initial annealed sample, a disc sample subjected to pressing with $50 \%$ thickness reduction, rods subjected to ECAP, disc and ring samples subjected to HPT and disc samples subjected to post-HPT annealing were evaluated in terms of Vickers microhardness, electrical conductivity and microstructures. For the ECAP samples, $10 \mathrm{~mm}$ diameter discs were cut at the mid-point of the rods along the direction perpendicular to the longitudinal axis. First of all, all samples were polished to a mirror-like surface and the Vickers microhardness was measured along the radii from the center to edge at 8 different radial directions with $0.5 \mathrm{~mm}$ increments. For each hardness measurement, a load of $200 \mathrm{~g}$ was applied for $15 \mathrm{~s}$. Second, for electrical conductivity measurements, miniature rods with a $0.5 \mathrm{~mm}$ square cross section and $9 \mathrm{~mm}$ length were cut from the $10 \mathrm{~mm}$ diameter discs at $2 \mathrm{~mm}$ away from the center, and from the $30 \mathrm{~mm}$ diameter discs at $1 \mathrm{~mm}$ away from the edge. Four-point electrical conductivity measurements were carried out using different currents in the range of $0-100 \mathrm{~mA}$. The electrical resistivity/conductivity was determined by Ohm's Law by measuring the produced voltage at central part of the miniature rods with $4 \mathrm{~mm}$ length. Third, for transmission electron microscopy (TEM), discs with $3 \mathrm{~mm}$ diameter were punched from $3.5 \mathrm{~mm}$ away from the disc centers. The $3 \mathrm{~mm}$ discs were ground mechanically to a thickness of $0.15 \mathrm{~mm}$ and further thinned with a twin-jet electro-chemical polisher using a solution of $15 \% \mathrm{HNO}_{3}, 15 \% \mathrm{C}_{3} \mathrm{H}_{5}(\mathrm{OH})_{3}$ and $70 \%$ $\mathrm{CH}_{3} \mathrm{OH}$ at $263 \mathrm{~K}$ under an applied voltage of $9 \mathrm{~V}$. TEM was performed at $200 \mathrm{kV}$ for microstructural observation and selected area electron diffraction (SAED) patterns were also taken from a region with $6.3 \mu \mathrm{m}$ diameter.

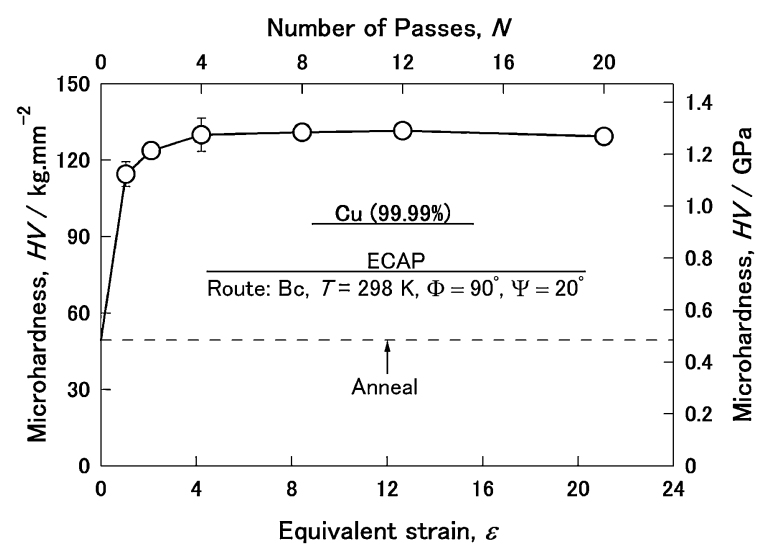

Fig. 2 Vickers microhardness plotted against equivalent strain for rodshape samples processed by ECAP after various numbers of passes.

\section{Results and Discussion}

Figure 2 plots the hardness variation with the equivalent strain for $\mathrm{Cu}$ rods processed by ECAP using route $\mathrm{Bc}$ for various numbers of passes. The hardness increases with increasing equivalent strain at an early stage of straining but saturates to a steady state at high strains where the hardness remains unchanged with further straining. The microhardness at the steady state is $132 \mathrm{Hv}$. The dependence of the hardness with respect to strain including the hardness level at the steady-state is similar to that reported earlier. ${ }^{12)}$

The hardness values are plotted against the equivalent strain in Fig. 3 after HPT processing at room temperature for $N=1$ and 12 revolutions and after post-HPT annealing at $433 \mathrm{~K}$ and $513 \mathrm{~K}$ for $2 \mathrm{~h}$. The hardness variations of as-deformed samples are essentially the same as the one reported in an earlier paper ${ }^{9}$ ) and the steady-state level, $132 \mathrm{Hv}$, is reached directly following the initial increase with straining. However, following the post-HPT annealing, the hardness initially increases with increasing strain and, after reaching a maximum and decreasing to a minimum, saturates to a constant level. The hardness values at the steady state are $80 \mathrm{Hv}$ and $86 \mathrm{Hv}$ after post-HPT annealing at $433 \mathrm{~K}$ and $513 \mathrm{~K}$, respectively. The hardness variations and the appearance of the hardness maximums after post-HPT annealing are similar to the ones reported in pure $\mathrm{Al}$ $(99.99 \%)^{38,39,42-44)}$ and pure $\mathrm{Mg}(99.9 \%)^{45)}$ subjected to HPT at room temperature. It is noted that the temperature of $433 \mathrm{~K}$ corresponds to $0.32 T_{\mathrm{m}}$, where $T_{\mathrm{m}}$ is the melting point, and $0.32 T_{\mathrm{m}}$ is equivalent to room temperature for $\mathrm{Al}$ and $\mathrm{Mg}$. Thus, this indicates unambiguously that static softening (due to recovery and/or recrystallization) can occur during HPT processing of $\mathrm{Cu}, \mathrm{Al}$ and $\mathrm{Mg}$ as suggested in an earlier paper. ${ }^{46)}$ Now, the major difference is that a hardness minimum appears in Fig. 3 before the steady state. The reasons for this hardness behavior are described below.

Details for the microstructural evolution of $\mathrm{Cu}$ during HPT were described in an earlier paper. ${ }^{18)}$ In the early stages of straining, dislocations accumulate and subgrains form with an increasing population within individual grains. Whereas most of grains contain many dislocations before the onset of the steady state, there are certain fractions of grains with a low density of dislocations at the steady state. It was suggested 


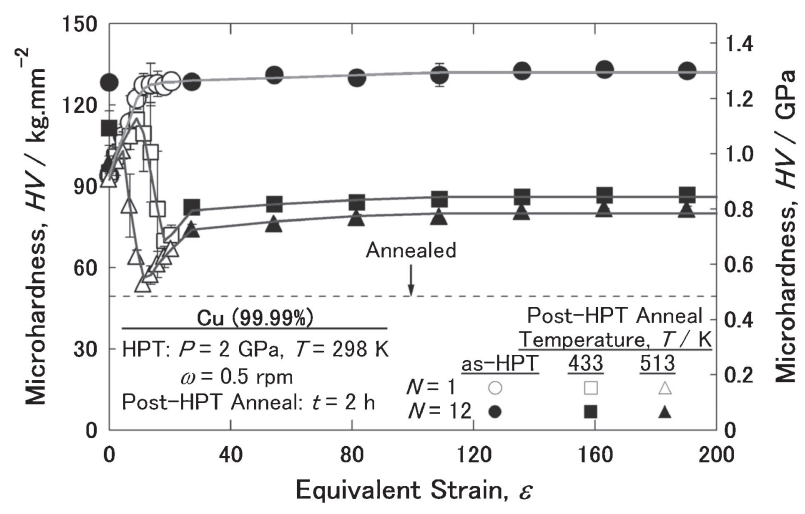

Fig. 3 Vickers microhardness plotted against equivalent strain for disc samples after HPT for 1 and 12 revolutions and post-HPT annealing for $2 \mathrm{~h}$ at $433 \mathrm{~K}$ and $513 \mathrm{~K}$.

that a dynamic recrystallization, which might have taken place during HPT processing, results in formation of grains with low dislocation density. It is well known that the density of dislocations is substantial in triggering the static softening and recrystallization. It is concluded that the hardness maximum at $\varepsilon=\sim 5$ in Fig. 3 appear when the dislocations density and stored energy after HPT processing is high enough to trigger the static softening after post-HPT annealing and the hardness minimum appears when the dislocations density and stored energy reaches the highest level after HPT processing.

Despite the fact that the equivalent strain is theoretically zero at the center of disc according to eq. (2), close inspection of Fig. 3 reveals three points: first, the hardness of HPT-processed disc samples at the disc center are higher than that of the starting annealed sample, second, the hardness at the disc center increases with increasing the number of revolutions from $N=1$ to 12 , and third, for sample processed after $N=12$, the hardness at the disc center is higher when compared to the areas away from the disc center after post-HPT annealing. These are due to two main reasons: ${ }^{40)}$ first, a small misalignment of the rotation axes between the lower and upper anvils may result in imposing an additional shear strain to the center of the disc, although the alignment was adjusted well within $\pm 0.01 \mathrm{~mm}$ in this study; second, in practice, hardness measurement at the exact center is difficult but the hardness values are measured within a circular area with $r=0.1 \mathrm{~mm}$ in radii. Considering $r=0.1$, estimations result in $\varepsilon=0.45$ and 5.4 for the disc center after $N=1$ and 12 revolutions, respectively.

Figure 4 shows the variation of (a) hardness and (b) electrical resisivity/conductivity with respect to the equivalent strain. The results were selected from a series of tests: pressing with $50 \%$ thickness reduction, ECAP processing after 20 passes, HPT processing using disc specimens after $N=1 / 4,1 / 2,3 / 4,1,2,4,12,16$ and 20 revolutions, HPT processing using ring specimens after $N=1$ and 3 revolutions, post-HPT annealing after $N=12$ revolutions, and ARB processing after 8 cycles. It is noted that the data for ARB were taken from Ref. 34) and the data for HPT were recorded from $2 \mathrm{~mm}$ away from the disc centers and $14 \mathrm{~mm}$ away from the ring centers. The following five important points are obtained from Fig. 3. (a)

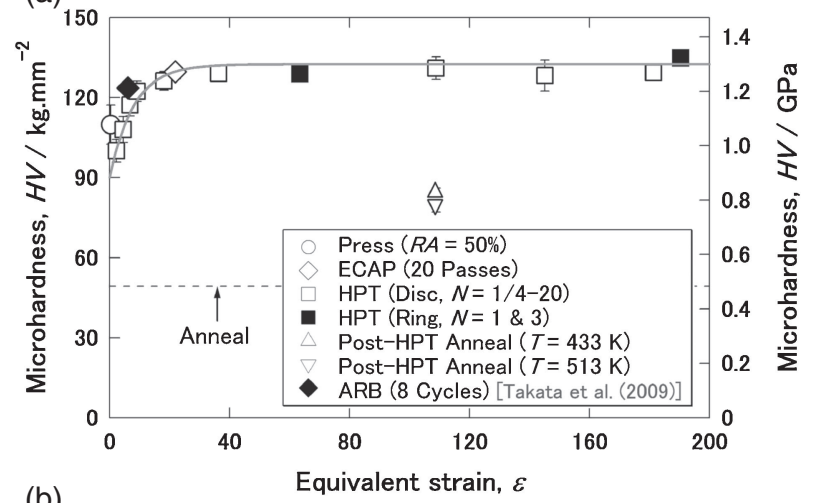

(b)

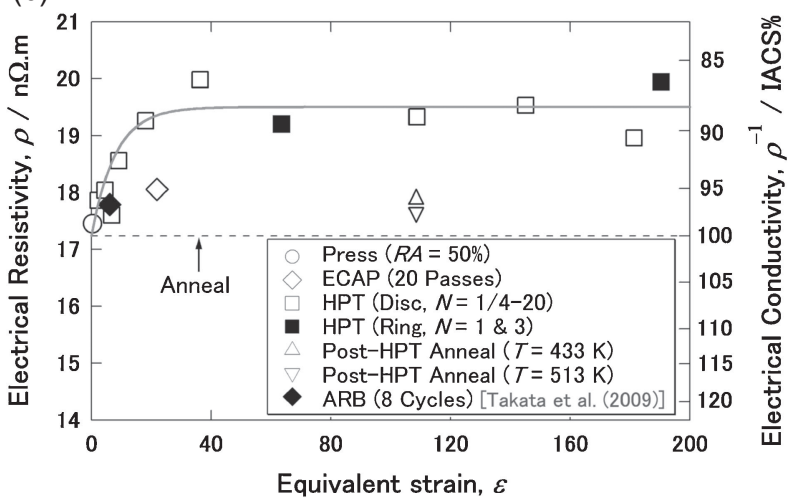

Fig. 4 (a) Vickers microhardness and (b) electrical resistivity/conductivity plotted against equivalent strain for samples processed by various methods.

First, both hardness and electrical resistivity values lie on unique single curves when plotted as a function of equivalent strain for samples processed by different methods. Second, the hardness and electrical resistivity increase with an increase in the equivalent strain at an early stage of straining but level off and enter into a steady state at equivalent strains more than $\sim 20$ where the values remain unchanged with further straining. Third, the hardness increases significantly $(\sim 270 \%)$ but the increase in the electrical resistivity is as small as $\sim 12 \%$ so that the electrical conductivity decreases slightly at the steady state when compared to the annealed condition. Fourth, the post-HPT annealing leads to a considerable decrease in the hardness but still maintains the hardness level as $\sim 160 \%$ when compared to the one at the complete annealed condition. The electrical conductivity improves significantly so that its level is recovered to $97 \%$. Fifth, the presence of the steady state was not reported in the earlier papers after ECAP processing ${ }^{21-23)}$ and after ARB processing ${ }^{32-34)}$ when electrical conductivity was plotted as a function of equivalent strain. It is most probable that the difference should be due to larger strains that are imposed in this study.

TEM micrographs and SAED patterns are shown in Fig. 5 from three samples subjected to different magnitudes of the equivalent strain: (a) $\varepsilon=22$ after ECAP for 20 passes, (b) $\varepsilon=80$ after HPT for 5 revolutions, and (c) $\varepsilon=160$ after HPT for 10 revolutions. These three samples correspond to the observations at the steady state. It is apparent from Fig. 5 that each microstructure consists of small grains with an average size of $200-400 \mathrm{~nm}$ having high angles of misor- 

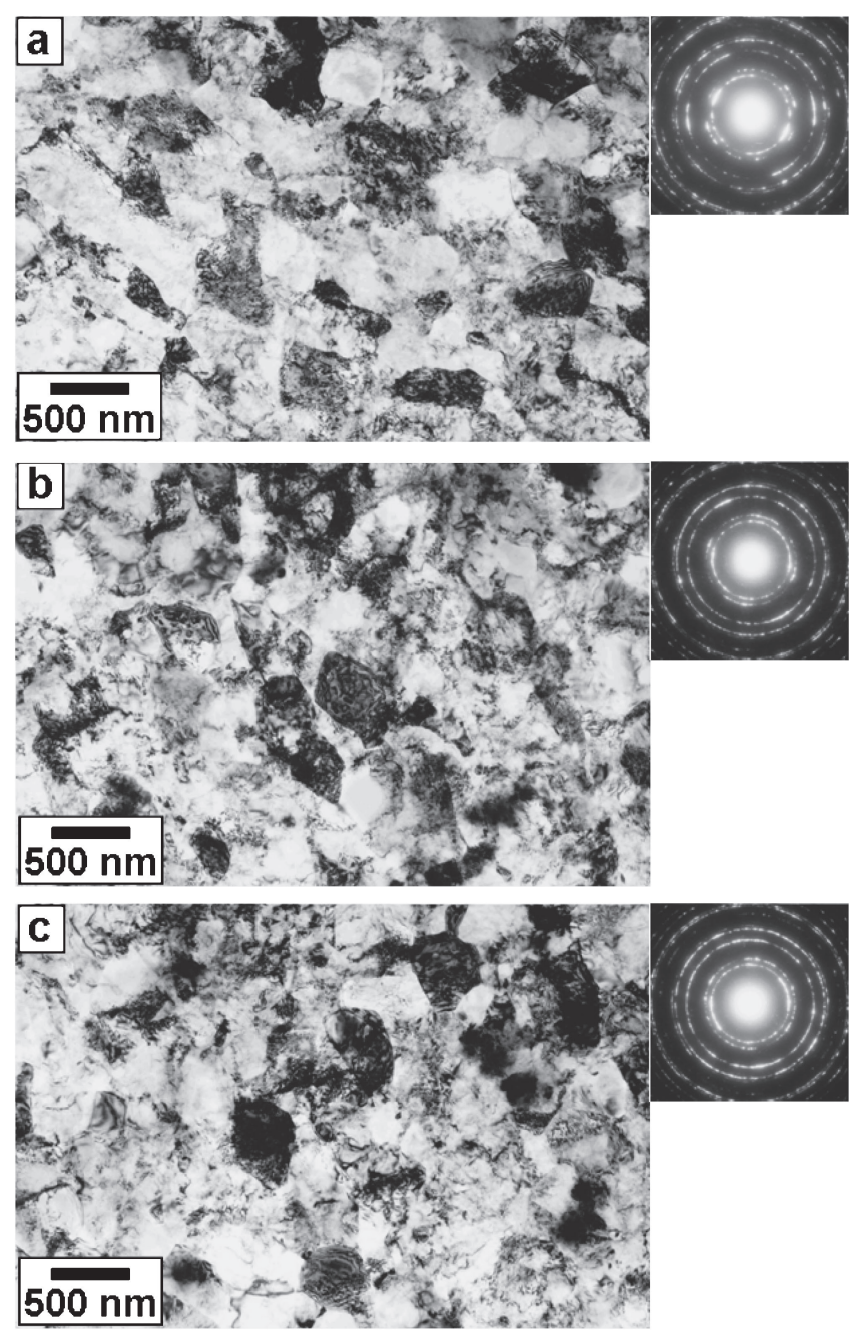

Fig. 5 TEM micrographs and SAED patterns for (a) a rod sample processed by ECAP for 20 passes $(\varepsilon=22)$, and disc samples processed by HPT for (b) 5 revolutions $(\varepsilon=80)$ and (c) 10 revolutions $(\varepsilon=160)$.

ientation as evident from the SAED with a well defined ring pattern. Inspection of Fig. 5 reveals that there are grains with a high density of dislocations while some grains contain a low dislocations density. Close examination of the microstructures reveals that the microstructures are reasonably the same for the three samples, indicating that the microstructure does not change at the steady state with straining. These microstructural features are consistent with the earlier observations. ${ }^{14)}$

Microstructures are shown in Fig. 6 for the steady state conditions after post-HPT annealing at (a) $433 \mathrm{~K}$ and (b) $513 \mathrm{~K}$ for $2 \mathrm{~h}$. The microstructures consist of grains with the sizes of $1-4 \mu \mathrm{m}$ after annealing at $433 \mathrm{~K}$ and of $2-6 \mu \mathrm{m}$ after annealing at $513 \mathrm{~K}$, where the grains are free of dislocations. It should be noted that many twins are visible in many grains and they are typical features observed after annealing of deformed metals and alloys with low stacking fault energies. ${ }^{47)}$ It is apparent that there is a high driving force for recrystallization in HPT-processed $\mathrm{Cu}$ due to high dislocation density and large area of grain boundaries. It is considered that the appreciable retainment of the higher hardness level but the improvement of the electrical conductivity closer to $\sim 100 \%$ after post-HPT annealing should be attributed to static softening and recrystallization.
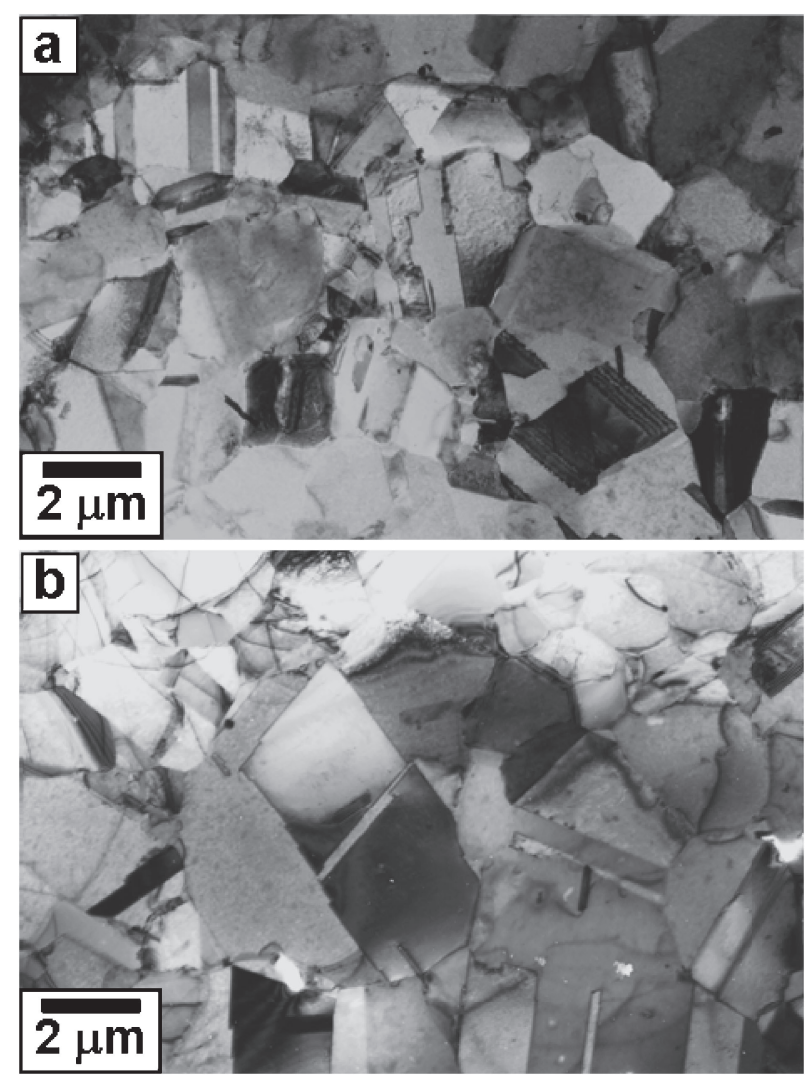

Fig. 6 TEM micrographs for disc samples after HPT processing for 12 revolutions and post-HPT annealing at (a) $433 \mathrm{~K}$ and (b) $513 \mathrm{~K}$ for $2 \mathrm{~h}$.

\section{Conclusions}

Pure $\mathrm{Cu}(99.99 \%)$ is processed by ECAP and by HPT using disc and ring specimens and the following conclusions were obtained.

(1) Both hardness and electrical resistivity increases with an increase in the equivalent strain at an early stage of straining, but saturates to a steady state at the equivalent strains more than $\sim 20$.

(2) Despite a marked increase in the hardness $(\sim 270 \%)$, the electrical conductivity decreases only by $\sim 12 \%$ at the steady state when compared to the annealed condition.

(3) When the HPT-processed samples are annealed at $433 \mathrm{~K}$ and $513 \mathrm{~K}$ for $2 \mathrm{~h}$, a maximum and a minimum hardness peaks appears with increasing strain, and this is followed by saturation to a steady state where the hardness remains unchanged with further straining. The hardness level at the steady state decreases when compared to the as-HPT-processed state but the hardness level as $\sim 160 \%$ is still maintained when compared to the annealed condition. The electrical conductivity is improved to more than $97 \%$ by the post-HPT annealing.

\section{Acknowledgement}

One of the authors (KE) thanks the Japan Society for Promotion of Science (JSPS) for a postdoctoral scholarship. This work was supported in part by a Grant-in-Aid for Scientific Research from the Ministry of Education, Culture, Sports, Science and Technology of Japan in the Innovative 
Area "Bulk Nanostructured Metals", and in part by Kyushu University Interdisciplinary Programs in Education and Projects in Research Development (P\&P).

\section{REFERENCES}

1) R. Z. Valiev, R. K. Islamgaliev and I. V. Alexandrov: Prog. Mater. Sci. 45 (2000) 103-189.

2) R. Z. Valiev, Y. Estrin, Z. Horita, T. G. Langdon, M. J. Zehetbauer and Y. T. Zhu: JOM 58 (2006) 33-39.

3) V. M. Segal, V. I. Reznikov, A. E. Drobyshevskiy and V. I. Kopylov: Russ. Metall. 1 (1981) 99-105.

4) R. Z. Valiev and T. G. Langdon: Prog. Mater. Sci. 51 (2006) 881-981.

5) P. W. Bridgman: Phys. Rev. 48 (1935) 825-847.

6) A. P. Zhilyaev and T. G. Langdon: Prog. Mater. Sci. 53 (2008) 893 979.

7) Y. Saito, N. Tsuji, H. Utsunomiya, T. Sakai and R. G. Hong: Scr. Mater. 39 (1998) 1221-1227.

8) R. Z. Valiev, Y. V. Ivanisenko, E. F. Rauch and B. Baudelet: Acta Mater. 44 (1996) 4705-4712.

9) R. Z. Valiev, I. V. Alexandrov, Y. T. Zhu and T. C. Lowe: J. Mater. Res. 17 (2002) 5-8.

10) F. Wetscher, A. Vorhauer, R. Stock and R. Pippan: Mater. Sci. Eng. A 387-389 (2004) 809-816.

11) R. Pippan, S. Scheriau, A. Taylor, M. Hafok, A. Hohenwarter and A. Bachmaier: Annu. Rev. Mater. Res. 40 (2010) 319-343.

12) S. Komura, Z. Horita, M. Nemoto and T. G. Langdon: J. Mater. Res. 14 (1999) 4044-4050.

13) H. S. Kim, S. I. Hong, Y. S. Lee, A. A. Dubravina and I. V. Alexandrov: J. Mater. Process. Technol. 142 (2003) 334-337.

14) X. Z. Liao, Y. H. Zhao, S. G. Srinivasan, Y. T. Zhu, R. Z. Valiev and D. V. Gunderov: Appl. Phys. Lett. 84 (2004) 592-594.

15) T. Hebesberger, H. P. Stuwe, A. Vorhauer, F. Wetscher and R. Pippan: Acta Mater. 53 (2005) 393-402.

16) A. Mishra, B. K. Kad, F. Gregori and M. A. Meyers: Acta Mater. 55 (2007) 13-28.

17) A. P. Zhilyaev, S. Swaminathan, A. A. Gimazov, T. R. McNelley and T. G. Langdon: J. Mater. Sci. 43 (2008) 7451-7456.

18) K. Edalati, T. Fujioka and Z. Horita: Mater. Sci. Eng. A 497 (2008) $168-173$.

19) G. Khatibi, J. Horky, B. Weiss and M. Zehetbauer: Int. J. Fatigue 32 (2010) 269-278.

20) X. H. An, S. D. Wu, Z. F. Zhang, R. B. Figueiredo, N. Gao and T. G. Langdon: Scr. Mater. 63 (2010) 560-563.

21) S. Han, C. Lim, C. Kim and S. Kim: Metall. Mater. Trans. A 36 (2005) $467-470$.
22) A. Habibi, M. Ketabchi and M. Eskandarzadeh: J. Mater. Process. Technol. 211 (2011) 1085-1090.

23) F. Higuera, J. A. Munoz and J. M. Cabrera: Mater. Sci. Forum 667-669 (2011) 713-718.

24) K. X. Wei, W. Wei, F. Wang, Q. B. Du, I. V. Alexandrov and J. Hu: Mater. Sci. Eng. A 528 (2011) 1478-1484.

25) M. Ashida, T. Hamachiyo, K. Hasezaki, H. Matsunoshita, M. Kai and Z. Horita: J. Phys. Chem. Solids 70 (2009) 1089-1092.

26) T. Hamachiyo, M. Ashida, K. Hasezaki, H. Matsunoshita, M. Kai and Z. Horita: Mater. Trans. 50 (2009) 1592-1595.

27) L. Zhang, A. Grytsiv, B. Bonarski, M. Kerber, D. Setman, E. Schafler, P. Rogl, E. Bauer, G. Hilscher and M. Zehetbauer: J. Alloy. Compd. 494 (2010) 78-83.

28) B. D. Long, M. Umemoto, Y. Todaka, R. Othman and H. Zuhailawati: Mater. Sci. Eng. A 528 (2011) 1750-1756.

29) D. V. Shangina, N. R. Bochvar and S. V. Dobatkin: Mater. Sci. Forum 667-669 (2011) 301-306.

30) H. Matsunaga, Z. Horita, K. Imamura, T. Kiss and X. Sauvage: Mater. Sci. Forum 667-669 (2011) 307-312.

31) Y. Champion, J. P. Couzinie, S. T. Nenez, Y. Brechet, R. K. Islamgaliev and R. Z. Valiev: Mater. Sci. Forum 667-669 (2011) 755-759.

32) Y. H. Jang, S. S. Kim, S. Z. Han, C. Y. Lim, C. J. Kim and M. Goto: J. Mater. Sci. 40 (2005) 3527-3529.

33) S. A. Hosseini and H. Danesh-Manesh: Mater. Design 30 (2009) 29112918.

34) N. Takata, S. H. Lee and N. Tsuji: Mater. Lett. 63 (2009) 1757-1760.

35) L. Ghalandari and M. M. Moshksar: J. Alloy. Compd. 506 (2010) 172178.

36) T. Akita, K. Kitagawa, K. Kita, M. Gotoh, Y. Hirose and N. Tsuji: J. Phys. Conf. Ser. 240 (2010) 012119.

37) Y. Iwahashi, J. Wang, Z. Horita, M. Nemoto and T. G. Langdon: Scr. Mater. 35 (1996) 143-146.

38) Y. Harai, Y. Ito and Z. Horita: Scr. Mater. 58 (2008) 469-472.

39) K. Edalati and Z. Horita: Mater. Trans. 50 (2009) 92-95.

40) K. Edalati, T. Fujioka and Z. Horita: Mater. Trans. 50 (2009) 44-50.

41) K. Edalati, Z. Horita and T. G. Langdon: Scr. Mater. 60 (2009) 9-12.

42) C. Xu, Z. Horita and T. G. Langdon: Acta Mater. 55 (2007) 203-212.

43) M. Kawasaki, B. Ahn and T. G. Langdon: J. Mater. Sci. 45 (2010) 4583-4593.

44) M. Kawasaki, R. B. Figueiredo and T. G. Langdon: Acta Mater. 59 (2011) 308-316.

45) K. Edalati, A. Yamamoto, Z. Horita and T. Ishihara: Scr. Mater. 64 (2011) 880-883.

46) K. Edalati, Y. Ito, K. Suehiro and Z. Horita: Int. J. Mater. Res. 100 (2009) 1668-1673.

47) H. Paul, J. H. Driver, C. Maurice and A. Piatkowski: Acta Mater. 55 (2007) 833-847. 